\title{
SEMÂNTICAS DA AMIZADE E SUAS IMPLICAÇÕES POLÍTICAS
}

\author{
Lívia Godinho Nery Gomes ${ }^{1}$ \\ Instituto de Psicologia - USP \\ Nelson da Silva Júnior ${ }^{2}$ \\ Instituto de Psicologia - USP
}

\begin{abstract}
A semântica da amizade tem sido articulada, historicamente, aos ideais de igualdade-fraternidade, caracterizando-se por uma semântica familialista, que associa o amigo à figura do irmão. No entanto, alguns autores apontam que a semântica familialista pautada na prerrogativa de intimidade e familiaridade privilegia processos de homogeneização $e$ supressão da alteridade, podendo configurar práticas intolerantes de desumanização e discriminação do outro. Eles propõem, portanto, a desarticulação amizade-familiaridade, destacando a amizade como relação intersubjetiva privilegiada de experimentação política, precisamente, por sua qualidade de imprevisibilidade no vínculo com a alteridade. A amizade, enquanto espaço imprevisto de experimentação, traz à tona a discussão da possibilidade de se repensar e reinventar as formas de relacionamento e subjetividade, num contexto contemporâneo de forte invidualismo e fragilidade dos laços públicos.
\end{abstract}

Descritores: Amizade. Alteridade. Experimentação.

1 Mestre pelo Programa de Psicologia Social e do Trabalho do Instituto de Psicologia da USP. O presente artigo refere-se a uma parte da discussão teórica da dissertação de mestrado intitulada "Semânticas da amizade e suas implicações políticas. Familialismo e alteridade entre amigos nas classes populares”, pesquisa realizada com apoio do CNPq, sob orientação do Prof. Nelson da Silva Junior. Endereço: Rua Peixoto Gomide, 742, apt 71, CEP 01409-000, São Paulo, SP. Telefone: (11) 32870584. Endereço eletrônico: liviagng@ig.com.br

2 Professor Doutor do Departamento de Psicologia Social e do Trabalho do Instituto de Psicologia da USP. Endereço: Rua Borges Lagoa, 908, apt 233, CEP 04038-002 São Paulo, SP. Telefone: (11) 55722448. Endereço eletrônico: nesj@terra.com.br 
- ste artigo pretende explicitar e discutir as implicações políticas das seção dos tradicionais discursos da amizade com os ideais de igualdade e fraternidade. Serão apontadas críticas de alguns autores que nos atentam para os movimentos permeados pela busca de uma "pretensa” igualdade que, em geral, desembocam em práticas intolerantes, de desumanização e discriminação do outro, produzindo armadilhas da exclusão e suas nefastas subseqüências.

Vários autores, dentre eles Derrida (1997) e Ortega (1999, 2000), têm alertado para os perigos dessa implicação dos discursos tradicionais de amizade com ideais de homogeneidade, nos modos de subjetivação associados à uma política fraternalista.

Derrida (1997), ao questionar a figura do irmão no centro dos grandes discursos de amizade, aponta as conseqüências desastrosas da concepção do amigo como um irmão (como um outro eu), implicada com valores semânticos de família que, por meio de discursos de equivalência de subjetividades - sujeitos idênticos -, pode se configurar nos piores sintomas de práticas nacionalistas, etnocêntricas, xenófobas.

Derrida (1997) também propõe uma ruptura na associação amizade fraternidade, pensando a amizade para além do parentesco, uma amizade sem a prerrogativa de proximidade e intimidade; e uma democracia por vir, mais inclusiva, desvinculada de todas as figuras de amizade que prescrevem fraternidade: a família e o endocêntrico grupo étnico. O autor apresenta uma possibilidade de ruptura em unificação, de uma amizade sem lar, de uma philia sem oikeiotès, privilegiando uma amizade voltada para a dissimetria, para a irredutível precedência do outro (em sua alteridade). Sonhando com uma amizade para além de proximidade, para além da família, Derrida (1997) propõe desfazer a associação de amizade e parentesco/familiaridade, rompendo com o que liga amizade a um "sendo-em-casa” ou "sendofechado-em si mesmo”, com o que articula amizade a todas as leis e lógicas de homogeneização e valores de padronização. 
Ele ainda alerta que, em nome de fraternidade, podem-se excluir as diferenças, em uma lógica violenta que anula a singularidade e reduz o outro ao mesmo, produzindo práticas intolerantes. Suas reflexões fundam-se em uma ética e cuidado do outro, concentrando-se em uma amizade que não pressupõe sujeitos coincidentes, afinidade, intimidade, familiaridade ou relação de parentesco, acolhendo o outro não como um irmão (lógica narcísica do outro eu e do ideal de amizade perfeita, como uma 'fusão de almas') e, sim, como o outro em sua alteridade, em uma amizade na qual os sujeitos não sejam idênticos entre si, de modo que se confundam e se misturem tal como um amálgama, uma amizade, portanto, não voltada para assimilação, absorção ou reciprocidade e, sim, para assimetria.

Derrida (1997) busca romper com a idéia da amizade como uma relação entre sujeitos idênticos, coincidentes entre si, presentes na semântica familiar da amizade, que compreende a relação com o amigo baseada numa reciprocidade - entendida como uma plena e perfeita identificação entre os amigos, que chegam a se confundir um com um outro num processo de mistura ou "fusão das almas.” Em outras palavras o autor questiona a supremacia da lógica do si mesmo e não da diferença, presente na semântica familiar, da amizade que associa o amigo ao irmão, compreendendo o vínculo de amizade como uma relação de simbiose, na qual os amigos se fundem como um amálgama.

Historicamente, também vale frisar as atrocidades ocorridas com o advento dos ideais nazistas, pautados em processos de homogeneização e padronização que, concebendo a raça ariana como a "raça pura”, disseminaram práticas e concepções racistas e violentas de perseguição e extermínio dos judeus, na busca "pela pureza e embelezamento do mundo". O filme $A$ Arquitetura da Destruição atesta que o Nazismo tinha, como um de seus princípios, o embelezamento do mundo e operou forças sem restrições em busca desse ideal racista de pureza, saúde e beleza; na procura do "sangue puro”, os inimigos eram os judeus, os miscigenados e os degenerados. Para manter a reprodução da ideologia totalitária de "preservar o sangue ariano”, o nazismo se apropriou da arquitetura, das artes, da medicina, do cinema etc. e os fez contribuir para a propagação dos ideais e práticas anti-semitas. O 
filme demonstra que películas da época retratam, de maneira extremamente distorcida, a lei da seleção natural de Darwin, afirmando que os homens vão de encontro a essa lei, ao permitir a propagação de formas de vida inferiores - leia-se judeus, miscigenados e doentes. Os judeus são mostrados como portadores de patologias através da História, e fazendo-se uma metáfora: judeus são bactérias, vermes, insetos, e o inseticida (gás letal) é a arma mais efetiva para acabar com eles.

Portanto, vê-se como o nazismo, fundado em processos de uniformidade e homogeneização, produz práticas de crueldade, de racismo, de intolerância. As forças nazistas não hesitaram em escravizar ou eliminar vizinhos “menos civilizados” ou tecnologicamente menos avançados. Bauman (1998) também destaca que o nazismo impeliu a tendência totalitária a seu extremo radical, condensando a complexidade moderna do problema da "pureza”, na questão da pureza da raça. Mostra-nos como um dos modos de a modernidade operar a ordem foi instaurando, no imaginário coletivo, o que ele denomina "sonho da pureza”. Esse autor delineia algumas características constitutivas da modernidade que visam a compor uma existência homogênea, pura, instaurando, na existência mesma, o ideal de pureza e higienização, num movimento de busca pelo controle dos acontecimentos, tornando os atos humanos previsíveis - na lógica da pureza que estabelece o “justo” e "conveniente" lugar de cada coisa e de cada um, na tentativa de produzir um mundo uniforme, planejado, puro. O ideal de pureza surge na modernidade como preservação, como uma assepsia ou planejamento para algo que se deseja impedir. Pureza contra sujeira, contra desordem, contra os “impuros”, contra a diversidade. Pureza como ordem: cada coisa ocupa funcional e estrategicamente seu lugar na busca por um ambiente controlado. Nesse processo de ordenação pela pureza, Bauman (1998) ressalta que o oposto da "pureza” - o sujo, o imundo, o refugo, o lixo irreciclável - são coisas "fora do lugar”, uma vez que "não são as características intrínsecas das coisas que as transformam em 'sujas', mas tão-somente sua localização e, mais precisamente, sua localização na ordem de coisas idealizadas pelos que procuram a pureza” (Bauman, 1998, p. 14). 
Mais especificamente no contexto contemporâneo, a "sujeira” da pureza pós-moderna, o lixo que precisa ser removido, os "fora do lugar” são aqueles que não podem participar do jogo consumista, os "consumidores falhos”, como afirma Bauman (1998). São os novos “impuros”, os quais não se ajustam ao mais atual modelo de pureza, dado que são incapazes de consumir diante das inúmeras possibilidades de escolhas que o mercado proporciona, tornando-se a "sujeira” que deve ser removida, já que sua presença não serve mais à nova ordem econômica capitalista, passando a representar um empecilho, um obstáculo à velocidade e ao movimento fluido do consumo. Na busca pela pureza, na adequação para um mundo habitável e ordenado, o que está em jogo, como sugere Bauman (1998), não é tanto a eliminação da "sujeira primária”, mas a "metassujeira”, em outras palavras, o que se visa é à prevenção da interrupção da rotina, ou seja, é a tentativa de prevenir um movimento não-habitual de questionamento de hábitos, valores, modos de relacionamentos cotidianos. Nesse sentido, esse autor ressalta que, no movimento de organização, de cuidado diário da pureza, evidencia-se a preocupação com os estranhos, que são vistos como perigo e ameaça, já que não partilham as estruturas e lógicas do grupo abordado, configurando-se, potencialmente, como questionadores, desestruturadores da ordem local. "É por isso que a chegada de um estranho tem um impacto de um terremoto... $\mathrm{O}$ estranho despedaça a rocha sobre a qual repousa a segurança da vida diária” (Bauman, 1998, p. 19).

Os mecanismos que operam a busca de pureza e ordem, portanto, tendem a evitar ou anular os estranhos, aqueles que potencialmente põem em questão o que parece inquestionável pelas pessoas locais; o estrangeiro não é bem visto, configurando-se como a "sujeira” que deve ser eliminada. Vê-se, então, a significação política e social da busca de pureza, da homogeinização e a gravidade de suas conseqüências para a convivência humana. Vimos, também, como outros autores, tais como Derrida (1997) e Ortega (2000), criticam a associação dos discursos e práticas da amizade com essa lógica da pureza, da homogeneidade, que implica a aniquilação e anulação do outro, configurando uma semântica de amizade apoiada na prerrogativa de familiaridade e intimidade e relações do tipo “panelinhas”, nas quais não há espaço 
para o estrangeiro/outro e, por isso mesmo, configuram-se como espaço pouco aberto à experimentação política.

Veremos agora, mais especificamente, como se constrói a anulação da alteridade nas estratégias discursivas tradicionais de amizade. Derrida (1997) e Ortega (2000) apontam como o modelo canônico e grego de amizade ligado à fraternidade utiliza-se de estratégias discursivas em torno da semântica familialista, produzindo um aniquilamento do outro (estrangeiro ou não-familiar), um regime de intolerância na busca de uma "pretensa" harmonização e uniformidade.

Ao contestarem o modelo fraternalista de amizade, Derrida (1997) e Ortega (2000) questionam a ideologia universalista de fraternidade que, em nome de uma suposta uniformidade, produz a exclusão e a desumanização do outro e o caráter agressivo/narcisista da supressão da alteridade, imbuído nos discursos tradicionais de amizade. Eles propõem uma ruptura na tradicional semântica de amizade em torno de: proximidade, hábito, consenso, intimidade, familiaridade etc., para pensar uma amizade além das metáforas familiares e fraternalistas, uma amizade aberta para o outro, que não exclua e suprima a singularidade; portanto, uma amizade que não é uma relação essencialmente hedonista de adaptação e assimilação, mas uma relação agonística, na qual o encontro com o outro implica um movimento de transformação - que requer esforço e dor, incorporando a idéia de desigualdade/conflito.

A proposta derridiana de desconstruir a ligação amizade-fraternidade e a sua tradicional semântica - familiaridade, intimidade, proximidade etc. -, pensando uma amizade além do referencial hegemônico familiarfraternalista, implica o movimento de abertura para o outro não como um outro eu, mas compreendendo-o como absolutamente outro; implica uma amizade que acolha e respeite o outro em toda a sua "estranheza”.

No amigo, não devemos reconhecer-nos para fortalecer nossa identidade. A relação de amizade poderia desenvolver uma sensibilidade para as diferenças de opinião e de gostos. Somente essa distância, esse agonismo, essa disposição a nos deixarmos questionar em nossas crenças e idéias, a modificarmos nossas opiniões através do 
relacionamento com o amigo, constituem a base de uma amizade para além da reciprocidade, do parentesco, da incorporação do outro. (Ortega, 2000, pp. 81-82)

Observamos que movimentos e discursos imbuídos do ideal de fraternidade, fundados em processos de homogeneização, harmonização, possuem um potencial discriminatório, podendo produzir práticas violentas de exclusão e de atrocidades humanas. Nesse sentido, podemos perceber a relevância do questionamento de autores como Derrida (1997) e Ortega (1999, 2000), propondo uma ruptura da associação dos discursos tradicionais de amizade com fraternidade e familiaridade, levando-nos a refletir a possibilidade de uma relação de amizade aberta ao outro em sua alteridade, desvinculada das lógicas de permutação - que fundam leis, políticas e uma moral da pura equivalência, equivalência do certo e da vingança, da justiça como princípio de equivalência e a lei do olho por olho - que a genealogia nietzschiana (Nietzsche, 1998) tem, implacavelmente, mas lembrado de que somos herdeiros.

Vimos que a proposta de desconstrução da associação amizadefraternidade, apresentada por Derrida (1997) e Ortega (1999, 2000), implica uma ruptura na tradicional semântica da amizade baseada na intimidade, familiaridade, uniformidade etc., para pensá-la como uma relação intersubjetiva (que não suprime as diferenças) de experimentação cuja potência subversiva e de imprevisibilidade aponta na constituição de novas formas de subjetivação que priorizem a singularidade e a autonomia.

\section{Amizade, Alteridade, Experimentação.}

Voltaremos nossa atenção, agora, mais especificadamente, para pensar a plausibilidade da proposta da amizade como relação de abertura ao outro em sua alteridade, constituindo-se como espaço de experimentação política imanente de irrupção do imprevisto - apontada por Arendt (1993), Derrida (1997) e Ortega (1999, 2000). 
Essa amizade da "boa distância”, da qual nos falam esses autores, compreende o outro em sua singularidade, em sua intangibilidade humana, no espaço intersubjetivo, no qual o "mundo" - no sentido arendtiano - aparece.

Figueiredo e Coelho Júnior (2003) destacam que, contrariamente à tradição filosófica moderna, que compreende o "Eu” como uma unidade autoconstituída, independente da existência de um "outro" singular e diferenciado, a tendência contemporânea em Psicologia, do socioconstrutivismo à Psicanálise, ressalta, cada vez mais, o reconhecimento do outro no processo de constituição de subjetividades singulares (ou de constituição do self). Portanto, esse novo movimento ético fundamenta-se na noção de intersubjetividade - noção que, segundo os autores citados, não fez sentido e foi rejeitada pelo pensamento moderno, que tem como marca epistemológica a oposição clássica sujeito/objeto.

A experiência intersubjetiva encontra-se no centro da compreensão contemporânea dos processos de constituição de subjetividade, configurando uma ética de imprescindibilidade do outro para a produção do si mesmo, na qual o outro aparece como irredutível, na sua alteridade absoluta. Figueiredo e Coelho Júnior (2003) mostram que é no trabalho de Lévinas (1993, 2005) que o outro é pensado de fato como uma radical alteridade, a qual sempre me precede e me excede numa relação de intersubjetividade traumática: a subjetividade nasce nessa dimensão intersubjetiva do encontro do outro que sempre requer esforço e trabalho, produzindo dor e sofrimento num processo de abertura e acolhimento do outro em sua estranheza, alteridade; essa experiência traumática do outro implica processos de transformações, deslocamento e reconstituição das partes implicadas.

A relação intersubjetiva para Lévinas (1993, 2005) é, portanto, sempre traumática porque implica transformações (e transformações implicam trabalho e dor); o contato com o outro sofre o inevitável impacto de adaptação incompleta, da impossibilidade de um perfeito ajustamento, sendo traumático porque causa fraturas e requer trabalho em processos de inadaptação entre singularidades. 


\subsection{O chamado do rosto: encontros traumáticos e alteridade.}

Lévinas (1993) pensa o encontro com o outro como uma relação traumática, na qual a presença desse outro impele, comanda a partir do seu rosto uma responsividade, entendida como responsabilidade pelo outro. $\mathrm{O}$ caráter ético do conceito levinasiano de rosto funda-se na compreensão de que seres humanos são vulneráveis uns aos outros, ao apelo do rosto do outro. A experiência de estar exposto a outrem implica já generosidade; o ser visitado por outro me traumatiza e me afeta, sendo impossível rescindir a responsabilidade por esse outro. A leitura levinasiana da relação intersubjetiva pressupõe que o encontro com o outro implica reverência: “(...) o rosto impõe-se a mim sem que eu possa permanecer surdo a seu apelo, ou esquecê-lo, quero dizer, sem que eu possa cessar de ser responsável por sua miséria. A consciência perde sua prioridade” (Lévinas, 1993, p. 60).

Nesse sentido, para Lévinas (1993), a relação com o outro é traumática, pois é essencialmente um espaço intersubjetivo em que alteridades se questionam e se desestabilizam, num movimento de não-incorporação, no qual o outro, diferentemente dos discursos tradicionais da amizade, nunca é englobável, assimilável. Na experiência de visitação por alguém, o rosto fica um tanto além de sua face, um tanto além de seu mundo.

Portanto, a dimensão ética da visitação é anunciada pela presença do rosto como uma ordem irrecusável - “a nudez do rosto é indigência e já súplica na retidão que me visa” (Lévinas 1993, p. 60) -, um mandamento que possibilita o questionamento da consciência, num movimento no qual diante da exigência do outro, "o Eu” tem a sua soberana coincidência consigo diluída, expulsando-se do repouso; identificação em que a consciência retorna triunfante a si mesma para repousar sobre si . O “eu”, ao perceber o rosto como outro alguém, questiona-se e se desestabiliza, esvaziando seu imperialismo e egoísmo, confirmando sua unicidade, uma vez que ninguém pode responder a esse rosto (ao outro) em seu lugar. O "eu" se questiona e se transforma nesse encontro em que é afetado pela presença de um rosto que lhe impele resposta e responsabilidade, e a forma com a qual se afeta, as 
maneiras como responde/responsabiliza-se também afetam a qualidade desse encontro, porque ele também produz questionamentos e transformações.

Então, na leitura de Lévinas (1993, 2005) sobre a intersubjetividade, o outro não é compreendido como um outro eu (como nos discursos tradicionais de amizade), mas como absolutamente outro que me questiona, destroçando a soberania do eu; a subjetividade humana surge, constitui-se, no encontro ético de acolhimento do outro como rosto, na sua absoluta estranheza. Nesse sentido, a alteridade é constitutiva da subjetividade. A sociabilidade na relação face a face constitui uma chamada, um apelo irresistível, pois me obriga e exige de mim uma resposta; a percepção do “absolutamente outro” nessa relação é inesgotável, insaciável, pois configura um encontro que me põe em fome crescente; a percepção de alguém alimenta aumentando a fome, o outro que me visita é como uma espécie de pão que se dá a comer sem desaparecer, sem diminuir. "O desejável não preenche meu Desejo, mas aprofunda-o, alimentando-me, de alguma forma, de novas fomes” (Lévinas, 1993, p. 56).

Essa imprescindibilidade do outro para a produção do si, que é central no pensamento de Lévinas (1993, 2005) - que concebe a relação intersubjetiva essencialmente como espaço de afetividade, de acolhimento do outro em sua alteridade, em que há afetações e transformações de subjetividade na situação face a face, na qual o outro aparece como irredutível, em alteridade absoluta -, encontra-se presente na discussão derridiana e foucaultiana de amizade como espaço de experimentação aberto ao outro, que não é idêntico a mim, possibilitando uma relação agonística de produção de subjetividades e de irrupção do imprevisto.

Segundo Ortega (1999), a compreensão da amizade como relação que não censura as diferenças e privilegia a alteridade no processo de subjetivação - entendido como espaço intersubjetivo - encontra-se no centro da leitura foucaultiana da amizade como experimentação. O movimento desconstrutivo da associação amizade-fraternidade, que compreende a amizade como uma relação que não pretende anular as diferenças, como um espaço agonístico de transformação de singularidades, possibilita pensar um diálogo ami- 
zade/intersubjetividade, já que o outro (amigo) é indispensável na constituição do si mesmo; a subjetividade humana não pode mais ser pensada sem o outro, como nos lembram Figueiredo e Coelho Júnior (2003), na sua alteridade absoluta.

De acordo com Ortega (1999), a dimensão intersubjetiva encontra-se presente no pensamento foucaultiano de política como ética, que compreende o sujeito como capaz de produzir resistência através das "tecnologias de si” ou "ascese”, com as quais ele pode transformar a si mesmo e construir uma forma de existência desejada, ou seja, uma transformação de si que visa à experimentação de novas formas de sociabilidade e existência. A intersubjetividade é indispensável na temática foucaultiana do cuidado de si, tendo em vista que é somente em um contexto intersubjetivo que o cuidado de si se constitui; o sujeito ético só se constitui pelo encontro com o outro. "Sem a presença do outro não se pode produzir nenhum auto-relacionamento satisfatório; o cuidado de si precisa do outro” (Ortega, 1999, p. 126).

Nesse sentido, a subjetividade e a sociabilidade possuem um caráter ético no encontro com o outro. A relação intersubjetiva tem um caráter "agonístico”, o outro é indispensável para a produção do si mesmo, pois, é no encontro com um outro, na situação face a face iluminada por Lévinas (1993, 2005), que os sujeitos envolvidos se incitam mutuamente, possibilitando um “abalo”, uma desestruturação que gera possíveis questionamentos e transformações de suas subjetividades. A amizade, na concepção foucaultiana, que destaca o encontro com a alteridade, aponta para o desafio e a incitação e não para a submissão ao outro, possibilitando a experimentação de novas formas de relacionamento que, como sugere Foucault (2004), não se esgotam na família e no matrimônio.

Segundo Ortega (1999), a amizade entendida na concepção foucaultiana, como uma "estética da existência”, como espaço de intersubjetividade "agonística”, em que é ressaltada a heterogeneidade no encontro com o outro, que não deve ser suprimida na busca de uniformidade, representa a possibilidade de experimentar e reinventar formas de existência, recusando modos de subjetividade e sociabilidade dominantes. 
A amizade enquanto espaço relacional de recriação de singularidades, entendida como uma amizade processual, de experimentação, possui um caráter transgressor, podendo romper formas fixas de sociabilidade, promovendo fissuras nos modelos de subjetivação e sociabilidade dominantes. "A dimensão ético-transgressiva da amizade consiste na recusa das formas impostas de relacionamento e subjetividade” (Ortega, 1999, p. 170).

1.2. Experiência discursiva da amizade e a experimentação política.

Arendt (1993), Derrida (1997), Foucault (2004) e Ortega (1999, 2000) trazem à tona a possibilidade de discussão das relações de amizade como espaço de criatividade e experimentação, que possibilita a experiência política do agir e falar, na concepção arendtiana dos termos, privilegiando, como nos aponta Certeau (1994), uma politização das práticas cotidianas, entendidas como "arte" ou "maneiras de fazer", dotadas de qualidades astuciosas e desviantes. Esse autor preocupa-se com os procedimentos populares cotidianos que jogam com os mecanismos de disciplina e não se conformam com ela. Ele ressalta os modos de proceder da criatividade cotidiana, as diferentes maneiras que marcam socialmente o desvio através de práticas ou "arte de fazer" - compreendidas como táticas na "invenção do cotidiano”.

Segundo Certeau (1994), as trajetórias, táticas e retóricas, nos processos de interações cotidianas, constituem estruturas de negociação e improvisação próprias da linguagem comum, configurando astúcias de outros interesses e desejos que não são nem determinados, nem captados pelo sistema dominante. Nesse sentido, as relações de amizade pertinentes à discussão que as compreende como espaço intersubjetivo, o qual possibilita atividades experimentais, podem configurar uma "rede de uma antidisciplina”, como sugere Certeau (1994). Assim se instaura a contrapartida do lado dos "dominados", através de práticas que constituem desvios, fazendo uma "bricolagem” com e na cultura dominante, sendo possível usar inúmeras metamorfoses de lei, segundo interesses e regras próprios.

Pensar a possibilidade da amizade como espaço de experimentação capaz de irromper formas fixas de subjetividade e sociabilidade, constituin- 
do uma forma de resistência política, representa um convite à alteridade, à consideração dos outros como estranhos, numa relação experimental designada pelo compromisso irreversível com o outro. Pensar a amizade, na concepção foucaultiana e derridiana, representa um convite a uma forma de contato desafiadora e inquietante, na qual é possível vivenciar o sentimento de certo mal-estar de "perda de referencial”, trazido pela experiência de revelação e alargamento de opiniões no encontro com outros; essa experiência desestabilizadora, na qual o familiar passa a ser interrogado, não é vivida sem reflexão e o que era estranho pode parecer familiar; essa experiência na qual se é devolvido pelos outros possui um caráter inesperado e imprevisível.

É nesse sentido que Derrida (1997) fala da amizade como um espaço aberto para o novo, para a experimentação, qualificado como uma condição de "talvez" (perhaps). Ele ressalta que a dimensão do "talvez" carrega a extrema alteridade, a possibilidade do outro; a amizade como talvez traz consigo a possibilidade do risco, da incerteza, da instabilidade, uma abertura para experimentar o novo e o indeterminado.

A imprevisibilidade é a marca dessa amizade instável, dinâmica, como espaço aberto para o acontecimento, para invenção, o que nos faz pensar em autores como Arendt (1993), Derrida (1997), Ortega (1999, 2000) entre outros. A amizade como talvez implica o movimento de desejo, de ação, constituindo, utilizando-se as palavras de Ortega (2000), a "experiência mesma do impossível”. Ortega (2000) utiliza o conceito de “programa vazio” para ressaltar o caráter processual e imprevisto da amizade, como metáfora para uma amizade aberta, uma relação por vir, espaço que possibilita a imaginação e criação de novas formas de relacionamento.

O inesperado e o surpreendente são qualidades inerentes à concepção política arendtiana de ação e discurso. Agir, no sentido arendtiano do termo, significa iniciar, começar algo novo humanamente revelado por meio de palavras. Através da ação e do discurso, os homens distinguem-se singularmente, revelando-se e manifestando-se uns aos outros. Agir é uma iniciativa que tem como ponto de partida um iniciador, envolvendo um caráter utópico, a preposição daquilo que ainda é sem lugar entre nós. 
Para Arendt (1993), a mais importante das virtudes políticas é a amizade. A relação de amizade se configura como espaço privilegiado do agir e do falar - experiências eminentemente políticas e inter-humanas. Agir, no sentido arendtiano do termo, é, antes de tudo, iniciar, começar o que não é previsto, o que ainda não existe entre nós, no mundo. Corresponde a um começo que se faz em palavras; a iniciativa é já um ato de linguagem. $\mathrm{O}$ primeiro lugar da utopia é a linguagem: quem aponta o que ainda não foi vivido ou compartilhado, em geral, o faz falando. A utopia assume um lugar incipiente, mas decisivo, mas mobilizador na linguagem.

Com a sua teoria performativa da ação, Arendt (2001) aponta uma ação política como acontecimento e começo, como interrupção de processos automáticos. As ações humanas se caracterizam pela ausência de limites e pela imprevisibilidade das conseqüências. $\mathrm{O}$ agir constitui uma história cujo desenlace é desconhecido. Em outras palavras, na esfera da ação política é precisamente o inesperado que acontece. Arendt (2001) utiliza a metáfora do milagre e da dimensão de natalidade para caracterizar a ação política, pois a capacidade de produzir milagres é inerente ao agir.

Como experiências intersubjetivas, o agir e o falar implicam a parceria, a companhia dos outros, a conquista da adesão dos outros mediante persuasão e não pela violência ou coerção, para que a ação desempenhe um ciclo completo de experiência inaugural, inovadora. É nesse sentido que aquele que age não é somente agente, mas precisa esperar pelos outros. "Pelo fato de que se movimenta entre e em relação a outros seres atuantes, o ator nunca é simples 'agente', mas também, e ao mesmo tempo, paciente. Agir e padecer são como as faces opostas da mesma moeda (...)” (Arendt, 2001, p. 203).

Segundo Arendt (2001), os discursos e feitos da ação só são deixados quando testemunhados e guardados pela memória dos outros. A ação se liga à alegria de aparição, de glorificação; a glória corresponde a uma luz incidente no agente pelo testemunho dos outros. O testemunho dos outros ilumina o agente. A glória é a luz que vem dos outros, o rosto do outro que ilumina retomando Lévinas (1993) - é a luz pública que parte do testemunho das ações por outros. Essa luminosidade política aparece por meio de uma inicia- 
tiva através de palavras, que somente se perfaz em companhia dos outros, em presença de quem as palavras ficam como que iluminadas, brilham. "Dada a tendência intrínseca de revelar o agente juntamente com o ato, a ação requer, para sua plena manifestação, a luz intensa que outrora tinha o nome de glória e que só é possível na esfera pública” (Arendt, 2001, p. 193).

Portanto, a amizade, na concepção arendtiana do termo, é respeito e interesse pela opinião dos outros, não depende de intimidade, consiste no gosto pela opinião do outro, configurando uma relação desconcertante, "agonística”, na qual é possível viver o deslocamento/questionamento do familiar, deslocando-se para o lugar dos outros. A amizade, concebida na acepção política arendtiana, possibilita experimentar a desestabilizadora condição de "vista embaçada", sentida ao enxergar o mundo através de "lentes outras”. Além dessa experiência de descolamento do familiar, vivida através de uma alteração de ponto de vista, a relação de amizade, entendida como experiência inter-humana do agir e do falar, possibilita a experiência de ser visitado por outros, num contexto desafiador de coragem e ousadia da aparição, pois, segundo Arendt (2001), é somente pela ação e discurso, que o agente aparece e pode revelar-se.

Para essa autora, a qualidade reveladora da ação e do discurso é inerente ao fato de serem experiências inter-humanas, ou seja, que emergem na convivência humana - que permite as dimensões performativas da ação humana e a possibilidade de revelação. Ação e discurso são as únicas formas de que os homens dispõem para "mostrar quem são", para "revelar ativamente suas identidades pessoais e singulares”, para revelar o “quem”, em contraposição a "o que” alguém é.

Nesse sentido, ação é falar, a iniciativa se dá por palavras para “chegar” ao outro. Os seres humanos são capazes de interromper, ultrapassar automatismos sociais, superar o automatismo - que vem da reiteração de hábitos - vivenciado na experiência de trabalhar e de estar com os outros na cidade, através do gesto ou da voz, instaurando uma possibilidade de experiência imprevista. A voz é capaz de disparar, entre nós, um processo que não poderia ser esperado. $\mathrm{O}$ inesperado sempre tem como ponto de partida um 
iniciador, autor, aquele que começa o imprevisto e chama atenção para o destino imprevisto; destino que só se perfaz quando esse que começou é acompanhado por outros humanos.

Portanto, agir, entendido como experiência política, implica a parceria, a companhia dos outros. A ação, nesse sentido, possui caráter não violento e não coercitivo, tendo em vista que ela necessita dessa parceria, alcançada pela persuasão, por meio de conversas e não pela violência, para desempenhar um ciclo completo de experiência inaugural, de experiência inovadora. É nesse sentido, de espaço de experimentação e diálogo, que a amizade é, por excelência, uma atividade política que potencializa o agir - no aspecto arendtiano do termo -, em outras palavras, a amizade instaura o agir, possibilitando iniciar, perfazer com os outros a iniciativa, conquistando sua adesão mediante a palavra, e não, mediante a coerção ou mando.

O aspecto político da amizade pode assim ser indicado no fato de a relação de amizade se configurar como espaço discursivo privilegiado, no exercício de considerar a opinião do outro (Arendt, 1993). A relação de amizade entendida como espaço intersubjetivo de igualdade política, tal como apontado por Arendt (1993), em que o agir e falar possibilitam uma condição de conversas horizontais, irrompendo circuitos de dominação, possibilita a apropriação da linguagem, utilizando-a de forma inventiva e singular, num processo de "bricolagem" da linguagem e da cultura - como nos lembra Certeau (1994) -, podendo transformá-las e re-significá-las. Esse autor ressalta o espaço da conversa ou diálogo como uma "arte de fazer”, como uma prática cotidiana (dentre as demais: ler, consumir, circular etc.) astuciosa e tática, num movimento de desvio ou micro-resistência, podendo instaurar rupturas e transformações.

Diferentemente dos espaços discursivos no interior das relações familiares, ou nas relações com o Estado, nos quais a diferença (de opiniões, de pontos de vista etc.) entre o sujeito e seu outro estão tradicionalmente limitadas pela autoridade desse outro, o espaço discursivo da amizade não estaria, em princípio, limitado pela autoridade do outro. Isso possibilitaria ao espaço discursivo da amizade uma condição de igualdade política apontada 
por Arendt (1993) - uma condição de abertura e expansão do pensamento do sujeito no encontro com seu outro. O inesperado, o diferente e o imprevisto poderiam ser instaurados por meio de uma palavra que não coage o sujeito com a força de sua autoridade, nem com a autoridade de sua força. A troca de opiniões, mais do que transmitir ao outro como o mundo deve ser visto, a partir de uma perspectiva, a priori, correta, permitirá a transformação espontânea do discurso a partir de uma diferença percebida e sustentada pelo outro.

A troca de opiniões instaurada no campo semântico entre amigos assume a especificidade da possibilidade de aprimoramento e relativização do pensamento, condição que não se adquire sozinho. Quem troca, quem conversa, é transportado para uma condição que supõe ultrapassar a sua opinião, abraçar a dos outros e produzir algo novo a partir desse deslocamento - o que estabelece uma dependência do outro para alcançar um lugar de opinião mais complexo, mais abrangente.

Além da experiência discursiva, a amizade como uma relação política aberta à experimentação, da qual nos falam Arendt (1993), Derrida (1997) e Ortega (1999, 2000), implica a dimensão afetiva do acolhimento e respeito ao outro em sua alteridade, como um espaço intersubjetivo no qual os sujeitos estão em mesma condição de revelação/aparição e de escuta acolhida e respeitosa - condição de igualdade política -, podendo mostrar quem são e conhecer os outros, num contexto cujo objetivo não é necessariamente coincidir com a opinião dos outros, não é afirmar e reiterar o que os outros falam, mas é expressar a opinião num movimento que implica a possibilidade de formar-se ou desestruturar-se na conversa.

A imprevisibilidade da concepção política de Arendt (2001) confere à amizade um espaço político privilegiado do agir e falar iminente de irrupção de experiências inaugurais, inéditas. As relações de amizade, portanto, são imbuídas de poder político, já que, segundo ela, o poder humano advém da reunião não violenta dos homens. O poder existe precisamente no fato de que os homens vivem e agem juntos. "O único fator material indispensável para a geração do poder é convivência entre os homens. Estes só retêm po- 
der quando vivem tão próximos uns aos outros que as potencialidades da ação estão sempre presentes [...]” (Arendt, 2001, p. 213).

A amizade, enquanto espaço imprevisto de experimentação, apontado por Arendt (1993), Derrida (1997) e Ortega (1999, 2000), traz à tona a discussão da possibilidade de se repensar e reinventar as formas de relacionamento e subjetividade, num contexto contemporâneo de forte individualismo e fragilidade dos laços públicos, no qual a vida pública se encontra destituída de sentido e as relações de amizade se configuram numa condição de liquefação, associada ao movimento de desintegração dos laços humanos.

\subsection{Amizade e contemporaneidade: laços frágeis, naufrágios urbanos}

Vários diagnósticos descrevem o mundo contemporâneo como uma época marcada por um forte individualismo em nosso convívio social, predominando um enfraquecimento na negociação de interesses comuns. Bauman (2001), por exemplo, indica o surgimento de uma nova categoria na sociabilidade contemporânea, aquela de espaços "públicos, mas não civis”, cuja principal característica "é a dispensabilidade de interação".

Mais especificamente no que diz respeito à amizade, esta sofreu, conforme demonstra Ortega (2000), um deslocamento progressivo para o interior do contexto da vida familiar, simultaneamente a um progressivo afastamento de sua origem propriamente política, em acordo com o movimento mais geral de despolitização e de esvaziamento do espaço público característico da modernidade. Em vários autores (Ortega, 2000; Rezende, 2002; Sennett, 1988; Vincent-Buffault, 1996), surgem interpretações do modo como a sociedade íntima - terminologia utilizada por Sennett (1988), que designa a intimidade e a psicologização das relações - está ligada a uma decomposição das formas de sociabilidade próprias dos séculos XVII e XVIII, entre elas, a amizade em sua vocação helênica, que foi marcadamente política (Ortega, 2000).

O contemporâneo esvaziamento do espaço público e o conseqüente rebaixamento político retratam a sociedade do consumo, na qual as preocupações e motivações sociais estão voltadas para os interesses individuais e 
privados, configurando a decadência do engajamento político e dos interesses coletivos. Bauman (2001), ao falar dos processos de individualização e desintegração dos laços públicos como marcas da contemporaneidade, aponta essa primazia do privado e o aniquilamento do sentido de público.

Esse contexto de esvaziamento do espaço público e de vida pessoal desmedida é marcado por agenciamentos neoliberais que, segundo Bauman (2001), visam a desmantelar os laços públicos e decompor a arte de negociar diferenças, operando para que o espaço público e o contato com estranhos sejam vistos com medo e ameaça.

Segundo Bauman (2001), essa decomposição do espaço público - terreno natural do político - configura-se por uma decadência do diálogo e da arte de negociar interesses comuns, gerando uma patologia da política fundada na fluidez/fragilidade dos laços humanos, que substitui o compromisso mútuo e a comunicação pelo distanciamento do outro, do diferente, do estranho, evitando-se a necessidade de contato e negociação. Essa técnica do desvio do "não fale com estranhos” é apontada por Bauman (2001) como marca da precarização política contemporânea e enfraquecimento dos laços e parcerias que "tendem a ser vistos e tratados como coisas destinadas a serem consumidas, e não produzidas”(Bauman, 2001, p. 187).

As relações de amizade, nesse cenário contemporâneo de debilitação política e de espaço público esvaziado de sentido, ainda permanecem articuladas à prerrogativa de reciprocidade e intimidade, constituindo-se em espaços públicos, mas não civis, como nos lembra Bauman (2001). É o caso dos shoppings centers, cafés, clubes etc., que se caracterizam pela dispensabilidade de interação, pois são, essencialmente, espaços de consumo - atividade irremediavelmente solitária -, que projetam o sentimento de segurança e conforto da casa/família, num contexto no qual o espaço público é visto como extremamente ameaçador.

Segundo Sennett (1988), “a visão intimista é impulsionada na proporção em que o domínio público é abandonado, por estar esvaziado” (p. 26). O espaço público - aqui entendido a partir da noção arendtiana: espaços coletivos de embates com a multiplicidade, a diferença, que produzam a vontade 
de agir, desconstruindo formas fixas de sociabilidade - torna-se destituído de sentido, predominando um enfraquecimento das parcerias e laços humanos, uma debilitação da capacidade criativa das pessoas, por meio de diversos dispositivos de uma subjetividade compreendida e investida no plano do individual, do âmbito da privacidade.

Esse autor, ao destacar o esvaziamento e despolitização do espaço público, típicos da sociedade intimista, também ressalta a primazia do narcisismo nas relações sociais, sendo a experiência de abertura para os outros sentida como destrutiva. Inserida nessa lógica familialista e intimista da sociedade, a amizade encontra-se diluída em seu sentido de experimentação voltada para o mundo, no sentido arendtiano de espaço público e político. Pode-se dizer que as relações de amizade, no atual contexto de individualismo em que as relações com os outros (em sua diferença/estranheza) são sentidas com medo e desconfiança, tornam-se espaços destituídos de experimentação do não-familiar, constituindo-se com a essência do que Sennet (1988) chama de “celebração do gueto”.

Configurando-se nessa lógica de “celebração do gueto”, as relações de amizade perdem a beleza da experiência política, apontada por Arendt (1993), de alargamento de opiniões no encontro com o outro, na qual é possível viver o sentimento inquietante e desestabilizador do questionamento de crenças e opiniões familiares, num movimento de "descolamento" do familiar que permite um deslocamento para ver o mundo no lugar dos outros. Pois, segundo Sennett (1988), a “celebração do gueto” visa a tornar a experiência humana íntima e familiar, sobrepujando o desconhecido, apagando as diferenças:

Aquilo que precisamente se perde com essa celebração é a idéia de que as pessoas só podem crescer através de processos de encontro com o desconhecido. Coisas e pessoas que são estranhas podem perturbar idéias familiares e verdades estabelecidas; o terreno não familiar tem uma função positiva na vida de um ser humano. Essa função é a de acostumar o ser humano a correr riscos. O amor pelo gueto, especialmente o gueto de classe média, tira da pessoa a chance de enriquecer as suas percepções, a sua experiência, e de aprender a mais valiosa de todas as lições humanas: a habilidade para colocar em questão as condições já estabelecidas de sua vida. (Sennett, 1988, pp. 359-360) 
A relação de amizade - compreendida a partir do seu caráter político ressaltado por Arendt (1993), Derrida (1997) e Ortega (1999, 2000), entre outros - atenta para a possibilidade de que os vínculos de amizade se configurem como relações de abertura ao outro, nas quais é possível experimentar deslocamentos a partir do ponto de vista do outro. Amizade como espaço “agonístico”, no qual o acolhimento do outro, numa condição de não indiferença, possibilitaria o colocar-se no lugar do outro, instaurando um pensar que busca um deslocamento de idéias e opiniões, que pode fazer emergir experiências inéditas. A amizade agiria, portanto, politicamente, na estrutura do discurso de cada um dos seus sujeitos. Entretanto, Ortega (2000) e Vincent-Buffault (1996) demonstram que, historicamente, nem todas as facetas da amizade são políticas. Seu campo semântico, historicamente determinado, possui poder de restringir ou ampliar o espaço de tal vocação política da amizade: a concepção social da amizade pode favorecer ou desfavorecer que o inesperado, o imprevisto, emergido por meio da conversa/diálogo, adquira legitimidade, tornando-se efetivo, constituindo-se como relação de experimentação e criação em comum àquilo que se partilha.

No contexto contemporâneo, no qual laços humanos são apropriados com brutal perversidade e transformados em objetos de consumo pelo mercado consumidor, Arendt (1993), Derrida (1997) e Ortega (1999, 2000) trazem a reflexão da possibilidade de a amizade configurar-se como espaço privilegiado de conversas, instaurando processos inovadores mediante palavras que podem se perfazer através da parceria, da adesão dos outros. Agir é um início, que se define pela irreversibilidade e pela imprevisibilidade, mas, ao mesmo tempo, uma forma de desestabilizar os modelos, de experimentar e criar novas formas de vida. A dimensão de imprevisibilidade é a marca da amizade como espaço de experimentação política, que se configura como vínculo agonístico, no qual os sujeitos podem se desestabilizar, numa condição de acolhimento e abertura, que facilitam o caminho para a disposição em deslocar-se de um ponto fixo, em desgarrar-se de seus referenciais e questioná-los, permitindo a irrupção de experiências inovadoras. 


\section{Lívia Godinho Nery Gomes e Nelson da Silva Júnior}

Gomes, L. G. N. \& Júnior, N. S. (2005). Semantics of friendship and politics implications. Psicologia USP, 16 (3), 119-142.

Abstract: The semantic of friendship has been associated, from an historical point of view, to the equality and fraternity ideals. In that way, friendship is thought of within the frames of a familial semantic that associates the friend to the figure of the brother. Indeed, some authors point out to the fact that the familial semantic privileges homogenization processes by ways of suppressing otherness itself. Also, this semantic can be blamed of fostering social intolerance attached to discriminative practices. Therefore, they consider of great importance the disarticulation friendship-familiarity, and try to understand the friendship mostly as a privileged intersubjective relation for political experimentation, for the unexpected quality in the bond with otherness matches better with the difference inherent to political life than equality ideals. Friendship, since it is thought of as an unexpected space of experimentation, brings about the discussion of the possibility of creating new forms of relationship and subjectivity in our contemporary social context, which is extremely individualistic and where the public bows more and more fragile.

Index terms: Friendship. Alterity. Experimentation.

Gomes, L. G. N. \& Júnior, N. S. (2005). Sémantiques de l'amitié et ses implications politiques. Psicologia USP, 16 (3), 119-142.

Résumé: La sémantique de l'amitié est liée, d'un point de vue historique, aux idéaux d'égalité et de fraternité. En effet, la figure de l'ami a fréquemment été associée à celle du frère, ce qui nous permet de la décrire comme une sémantique essentiellement "familiale". Or, de plus en plus certains auteurs dénoncent le fait que cette sémantique "familiale", lorsque elle se fonde sur le sens d'intimité et homogénéité, tend aussi à supprimer l'altérité, ce qui peut être à l'origine des practiques régies par l'intolérance, par inhumainité et par la discrimination. C'est dans ce sens qu'ils proposent la cission sémantique entre amitié et familiarité, et soulignent comme l'essentiel dans l'amitié surtout le rapport intersubjectif d'expérimentation politique, lorsque celui-ci se définit à partir de l'imprévoyance dans le lien avec l'altérité. De ce fait, et surtout dans une culture marquée par l'individualisation et la fragilité des liens publiques

comme la nôtre, l'amitié, pensée comme espace d'imprévoyance et 
d'expérimentation invite à la discussion la possibilité de la réinvention des rapports sociaux et des sujets.

Mots-clés: Amitié. Altérité. Expérimentation.

\section{Referências}

Arendt, H. (1993). A dignidade da política: ensaios e conferências (H. Martins, trad.). Rio de Janeiro: Relume Dumará.

Arendt, H. (2001). A condição humana (10a ed., R. Raposo, trad.). Rio de Janeiro: Forense Universitária.

Bauman, Z. (1998). O mal-estar da pós-modernidade (M. Gama \& C. M. Gama, trads.). Rio de Janeiro: Jorge Zahar.

Bauman, Z. (2001). Modernidade líquida (P. Dentzien, trad.) Rio de Janeiro: Jorge Zahar.

Certeau, M. (1994). A invenção do cotidiano-artes de fazer (L. Giard, trad.). Petrópolis, RJ: Vozes.

Derrida, J. (1997). Politics of friendship (G. Collins, trad.). New York: Verso.

Figueiredo, C. L., \& Coelho Júnior, N. E. (2003). Patterns of intersubjetivity in the constituition of subjetivity: dimensions of otherness. Culture e psychology, 9(3), 193-208.

Lévinas, E. (1993). Humanismo do outro homem (P. S. Pivatto, trad.). Petrópolis, RJ: Vozes.

Lévinas, E. (2005). Entre nós. Ensaios sobre a alteridade (2a ed., P. S. Pivatto, trad.). Petrópolis, RJ: Vozes.

Nietzsche, F. W. (1998). Genealogia da moral: uma polêmica (3a ed., P. C. Souza, trad.). São Paulo: Companhia das Letras.

Ortega, F. (1999). Amizade e estética da existência em Foucault. Rio de Janeiro: Graal.

Ortega, F. (2000). Para uma política da amizade: Arendt, Derrida, Foucault. Rio de Janeiro: Relume Dumará.

Rezende, B. C. (2002). Os significados da amizade: duas visões de pessoa e sociedade. Rio de Janeiro: Editora FGV. 


\section{Lívia Godinho Nery Gomes e Nelson da Silva Júnior}

Sennett, R. (1988). O declínio do homem público: as tiranias da intimidade (8a ed., L. A. Watanabe, trad.). São Paulo: Companhia das Letras.

Vincent-Buffault, A. (1996). Da amizade. Uma história do exercício da amizade nos séculos XVIII e XIX (M. L. X. A. Borges, trad.). Rio de Janeiro: Jorge Zahar.

Recebido em: 15.09.2004

Revisto em: 7.02.2005

Aceito em: 5.03.2005 